\title{
LAND USE/LAND COVER CHANGE DETECTION USING MULTI-TEMPORAL SATELLITE DATASET: A CASE STUDY IN ISTANBUL NEW AIRPORT
}

\author{
D. Akyürek ${ }^{1}$, Ö. Koç ${ }^{1}$, E.M. Akbaba ${ }^{1,}$ F. Sunar ${ }^{2}$ \\ ${ }^{1}$ ITU, Civil Engineering Fac., Geomatics Department, Undergraduate Program, 80626 Maslak Istanbul, Turkey \\ (akyurekd, kocoy, akbabaec,)@itu.edu.tr \\ ${ }^{2}$ ITU, Civil Engineering Fac., Geomatics Department, 80626 Maslak Istanbul, Turkey \\ fsunar@itu.edu.tr
}

KEY WORDS: Multi-temporal satellite dataset, Land Use/Land Cover, Landsat-8, Sentinel 2A, Change detection

\begin{abstract}
:
In recent years, especially in metropolitan cities such as Istanbul, the emerging needs of the increasing population and demand for better air transportation capacity have led to big environmental changes. One of them is originated due to the construction of the new airport (Istanbul Grand Airport - IGA), located on the Black Sea coast on the European side of Turkey and expected as "The biggest hub in Europe" by the early 2020s. The construction has five phases and first construction phase is scheduled to finish up by the end of 2018 .

With an advanced space technologies including remote sensing, environmental consequences due to Land Use/Land Cover changes (LULC) can be monitored and determined efficiently. The aim of this paper is to analyse LULC changes especially in the forest areas and water bodies by using two different satellite image dataset. In this context, supervised classification method and different spectral indices are applied to both Landsat-8 (2013-2017) and Sentinel 2A (2015-2017) image datasets to demonstrate the total and annual changes during the construction of the first phase. The efficiency of two datasets is outlined by comparison of the output thematic map accuracies.
\end{abstract}

\section{INTRODUCTION}

Forests are the main core of the ecological system that is habitat of numerous animals and plants. Despite having its importance, deforestation which is basically defined as clearing the forests, has emerged due to both natural hazards and human needs that come out with increasing population. Among these two deforestation types, the man-made deforestation is mainly caused by urban needs. Istanbul as the largest city in Turkey, is one of the most striking examples for the man-made deforestation due to having 14.6 million populations (in December 2016 according to the Turkish Statistical Institute). It is expected that its population will increase to approximately 16 million in 2020 and will face a serious urbanization problem.

One of the problem foreseen will be related to the transportation since the city's transportation infrastructure is not sufficient with the urban growth and sprawl expected. Even though Istanbul has two biggest airports (Sabiha Gökçen Airport \& Istanbul Atatürk Airport), they are not sufficient to handle the annual air cargo and passenger capacities. According to METU/MATPUM (Middle East Technical University/Research and Implementation Centre for Built Environment and Design), in 12 years, the expected passenger capacity will reach to 118.3 million and air cargo carriage will be around 2.5 million tons (Georgieva et al., 2015). This leads to construction of a new airport which is expected to be "The biggest hub in Europe". IGA (Istanbul Grand Airport), which will be the new airport of Istanbul, has been under construction since 2015, and the construction has five phases (1a, 1b, 2, 3, and 4). The $80.5 \%$ of construction area was covered with forest and plant cover (Georgieva et al., 2015).

Thus, in this study, the striking changes in the first phase (1a) of the construction showing the deforestation in the area was examined using remote sensing technology. In this context, supervised classification was performed to detect and monitor the land use/land cover (LULC) changes using multi-temporal image datasets from Sentinel 2A MSI (Multi Spectral Instrument) and Landsat 8 OLI/TIRS (Operational Land Imager/Thermal Infrared Sensor). Moreover, different spectral indices such as Normalized Difference Vegetation Index (NDVI), Bare Soil Index (BI) and Normalized Difference Soil Index (NDSI) were also applied to assess the changes in the vegetation.

\section{STUDY AREA AND DATA}

\subsection{Study Area}

The study area is approximately 57,384 hectares located in Arnavutköy, European side of the Istanbul (Figure 1). The study area consists of the area of Istanbul Grand Airport (IGA) which locates on Black Sea coast and $40 \mathrm{~km}$ Northwest of Istanbul, numerous water bodies and forestry areas. The construction area of IGA is 7,659 hectares and 6,172 hectares of this area is a forest area (Georgieva et al., 2015). These water bodies are Kulakçayırı Lake, west part of Duru Lake and several water bodies in almost lake size; besides, the forestry areas are North Forests that are western side of the Belgrade Forest, Sevgililer Forest and forestry area in Durusu. 
Additionally, the administrative authorities such as Istanbul Regional Directorate of Forestry, Çatalca Forestry Operation Directorate and Istanbul Forestry Operation Directorate who are responsible to manage forestry regions are located in the borders of study area.

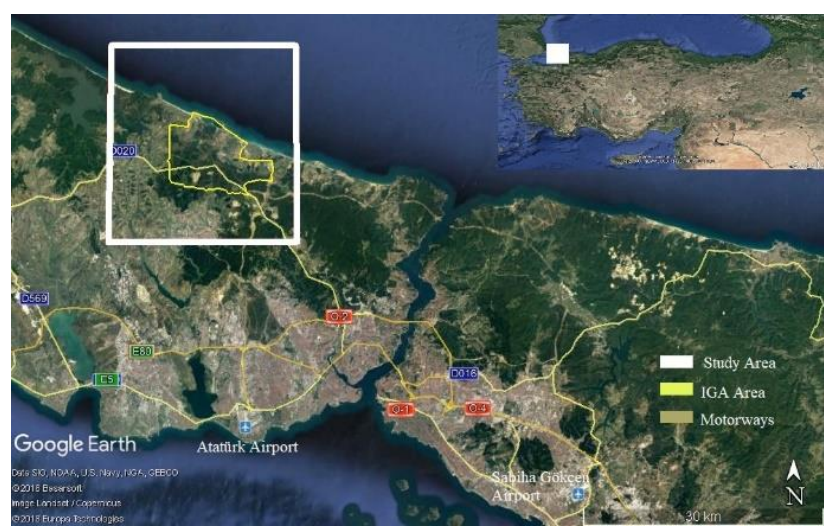

Figure 1. The map of the study area - Istanbul Grand Airport (C2017, Google Earth).

\subsection{Datasets}

In the analyses, 4 Landsat 8 OLI/TIRS data (from USGS Archive) and 3 Sentinel 2A MSI data (from Copernicus Open Access Hub) acquired respectively in 2013-2017 and 20152017 periods, were used to monitor and evaluate the annual environmental changes caused by the IGA construction in the study area (Table 1). The cloudless datasets belonging to approximately same season were selected to avoid the seasonal changes as much as possible. The characteristic of the Sentinel 2A MSI and Landsat $8 \mathrm{OLI} / \mathrm{TIRS}$ datasets used are given in Table 2 .

\begin{tabular}{|c|c|c|}
\hline Years & $\begin{array}{c}\text { Landsat 8 } \\
\text { OLI/TIRS }\end{array}$ & $\begin{array}{c}\text { Sentinel 2A } \\
\text { MSI }\end{array}$ \\
\hline 2013 & $30 / 07 / 2013$ & No data \\
2014 & $21 / 10 / 2014$ & No data \\
2015 & $06 / 09 / 2015$ & $12 / 08 / 2015$ \\
2017 & $22 / 07 / 2016$ & $08 / 05 / 2016$ \\
& $25 / 07 / 2017$ & $12 / 07 / 2017$ \\
\hline
\end{tabular}

Table 1. The acquisition dates of datasets used.

\section{METHODOLOGY}

The basic image processing steps applied in order to determine and analyse the changes due to airport construction are given in Figure 2 and explained in the following subsections briefly.

\begin{tabular}{|c|c|c|c|c|}
\hline \multirow{2}{*}{ Bands } & \multicolumn{2}{|c|}{ Sentinel 2A MSI } & \multicolumn{2}{c|}{ Landsat 8 OLI/TIRS } \\
\cline { 2 - 5 } & $\begin{array}{c}\text { Spectral } \\
\text { resolution } \\
(\mu \mathrm{m})\end{array}$ & $\begin{array}{c}\text { Spatial } \\
\text { resolution } \\
(\mathrm{m})\end{array}$ & $\begin{array}{c}\text { Spectral } \\
\text { resolution } \\
(\mu \mathrm{m})\end{array}$ & $\begin{array}{c}\text { Spatial } \\
\text { resolution } \\
(\mathrm{m})\end{array}$ \\
\hline B1 & $0.431-0.457$ & 60 & $0.435-0.451$ & 30 \\
B2 & $0.448-0.546$ & 10 & $0.452-0.512$ & 30 \\
B3 & $0.538-0.583$ & 10 & $0.533-0.590$ & 30 \\
B4 & $0.646-0.684$ & 10 & $0.636-0.673$ & 30 \\
B5 & $0.694-0.713$ & 20 & $0.851-0.879$ & 30 \\
B6 & $0.731-0.749$ & 20 & $1.566-1.651$ & 30 \\
B7 & $0.768-0.796$ & 20 & $2.107-2.294$ & 30 \\
B8 & $0.763-0.908$ & 10 & $0.503-0.676$ & $\begin{array}{c}15 \mathrm{~m} \\
(\text { Pan })\end{array}$ \\
B8A & $0.848-0.881$ & 20 & & 30 \\
B9 & $0.932-0.958$ & 60 & $1.363-1.384$ & 30 \\
B10 & $1.336-1.411$ & 60 & $10.60-11.19$ & $100^{*}$ \\
B11 & $1.542-1.685$ & 20 & $11.50-12.51$ & $100^{*}$ \\
B12 & $2.081-2.323$ & 20 & & \\
\hline$*$ TIR bands are acquired at $100 \mathrm{~m}$ resolution, and resampled to \\
\end{tabular}

Table 2. The characteristics of Sentinel 2A and Landsat 8 datasets used.

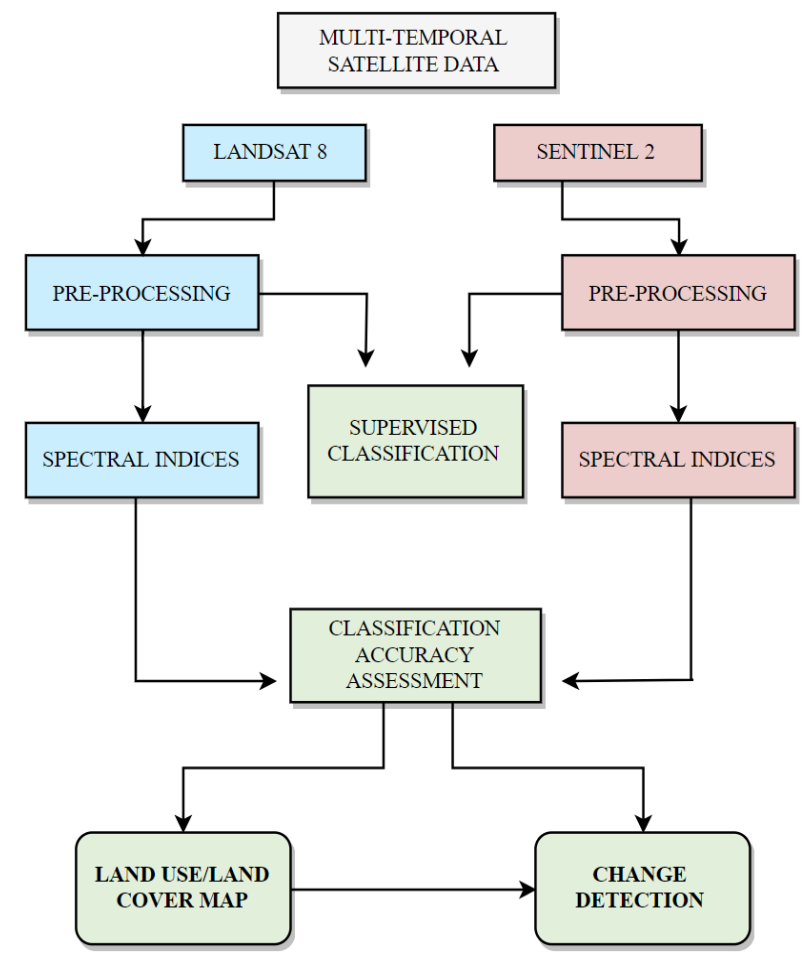

Figure 2. Flow chart used in the study. 


\subsection{Pre-processing}

Since all Landsat 8 OLI/TIRS images downloaded from the USGS Archive were already orthorectified, as a first step, the study area $\left(800 \times 800\right.$ pixels $-567000 \mathrm{~km}^{2}$ in total) was subsetted from all the Landsat 8 image dataset used. The Sentinel 2A MSI was also subsetted in a same manner after being rectified to Landsat 8 dataset. Since these 2 datasets having different spatial and spectral resolutions, the analysis was conducted for two different datasets. In the processing, as a first image dataset, Landsat 8 data with first 7 spectral bands having $30 \mathrm{~m}$ resolution was used to detect the annual gradual changes. For the second dataset, the spectral bands of Landsat 8 data having similar spectral band ranges with Sentinel 2A were selected and used to assess the efficiency of two datasets in thematic mapping.

Radiometric correction has not been made since image analyses is performed by post-classification change detection analysis done using cloudless image datasets.

3.1.1 Geometric Correction: To analyse the image pixel by pixel, registration process is performed to conform the pixel grids of one image to another using ground control points (GCPs) which were chosen adequately throughout the images. Geometric correction was performed for all Sentinel 2A images by taking the 2013 Landsat 8 image as a reference (master) image. Image to image registration was performed with \pm 0.5 root-mean-square $( \pm \mathrm{rms})$ accuracy. As a resampling method, the Nearest Neighbour resampling algorithm was chosen not to alter the value of the original input pixels-

\subsection{Spectral Indices}

To indicate relative abundance of features of interest, spectral indices which are combinations of surface reflectance at two or more spectral bands are widely used in image processing. Although the vegetation indices such as NDVI are the most popular type, but other indices used for burned areas (BAI), soil (NDSI) etc., are also being used to distinguish different features in the image.

In this study, the Normalized Difference Vegetation Index (NDVI) was applied for all datasets to distinguish vegetation from other LULC classes and also see the changes in vegetation class (Figure 3). Additionally, for distinguishing soil class from other LULC classes, the Normalized Difference Soil Index (NDSI) and Bare Soil Index (BI) were used respectively for Landsat 8 and Sentinel 2A data.

\subsection{Supervised Classification}

In the supervised classification, training areas that represent different surface cover types were identified based on actual surface cover types by analyst. The training set should have adequate number of independent samples for each class; moreover, it should be exhaustive and formed by samples exhibit the intraclass variability (Muñoz-Marí et al., 2007). After that, these specifically categorized training areas were used to recognize similar areas for each class by statistical algorithms.

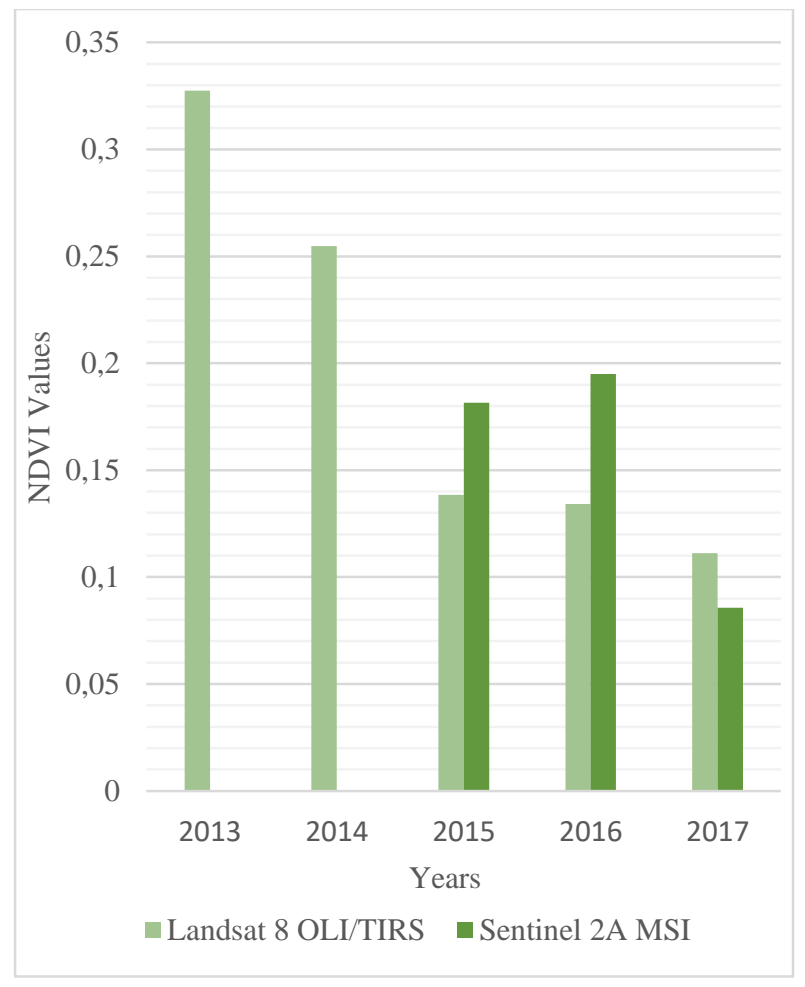

Figure 3. Vegetation changes detected by multi-temporal NDVI data in the construction area.

The nine classes which were sea, artificial lakes, highly vegetated area, sparse vegetated areas, soil 1, soil 2, sand, construction and road were taken into consideration. Supervised Maximum Likelihood (ML) classification method based on the Bayes theorem, assumes the statics of each class in each band have normal distribution and probability of given pixels is calculated depends on class of pixel. It makes use of a discriminant function to assign pixel to the class with the highest likelihood (Ahmad and Quegan, 2012).

\section{APPLICATION \& RESULTS}

To monitor annual gradual changes due to airport construction and its effects, change detection analysis was applied by comparing the annual thematic maps produced. Among the nine classes considered in the supervised classification, the airport construction class and other classes (highly vegetated area, sea, artificial lakes and road) which have interconnected with the main class were examined. The results of the changes were given in terms of percentage (\%) and hectare (ha).

\subsection{Image Classification \& Accuracy Assessment}

Supervised (ML) classification method was used for quantitative analysis of Landsat 8 and Sentinel $2 \mathrm{~A}$ datasets. The annual LULC maps of the new airport area produced were evaluated with the traditional error matrix that consists of producer and user accuracies developed by comparing randomly and independently selected test pixels with the ones used in classification. The Overall accuracies and Kappa 
coefficients of the all Landsat 8 and Sentinel 2A classifications are given in Table 3.

\begin{tabular}{|c|c|c|c|}
\hline Satellite & $\begin{array}{c}\text { Acquisition } \\
\text { date }\end{array}$ & $\begin{array}{c}\text { Overall } \\
\text { accuracy }(\%)\end{array}$ & $\begin{array}{c}\text { Kappa } \\
\text { coefficient }\end{array}$ \\
\hline & $30 / 07 / 2013$ & 99.67 & 0.97 \\
\cline { 2 - 4 } & $21 / 10 / 2014$ & 99.66 & 0.96 \\
\cline { 2 - 4 } & $06 / 09 / 2015$ & 97.81 & 0.73 \\
\cline { 2 - 4 } & $22 / 07 / 2016$ & 99.60 & 0.95 \\
\cline { 2 - 4 } Landsat & $25 / 07 / 2017$ & 99.28 & 0.93 \\
\hline \multirow{3}{*}{$\begin{array}{c}\text { Sentinel } \\
\text { 2A MSI }\end{array}$} & $12 / 08 / 2015$ & 99.57 & 0.92 \\
\cline { 2 - 4 } & $08 / 05 / 2016$ & 99.87 & 0.98 \\
\cline { 2 - 4 } & $12 / 07 / 2017$ & 99.96 & 0.95 \\
\hline
\end{tabular}

Table 3. The accuracy assessment of the Landsat 8 and Sentinel 2A classifications.

Since Kappa coefficient is considered more powerful than the others (Jensen, 2005), results were evaluated according to Kappa coefficient. As seen in the Figure 4, Sentinel 2A classification showed slightly higher accuracies than Landsat 8. It is thought that this is resulted due to its better spatial resolution that enables to select easier and more accurate training areas in the training step.

\subsection{Change Detection Analysis}

In change detection analysis, remotely sensed data is useful to monitor the land use/land cover changes (Singh,1989). Thus, except years 2013 and 2014, both Landsat 8 and Sentinel 2A, all data sets were used in order to monitor the annual changes. The 2013 Landsat 8 data was used for reference data for 2015 Sentinel 2A. After the image classification step, the post classification change detection was performed and evaluated with "from-to" change information (Macleod and Congalton, 1998). Both sea and artificial lakes classes are represented as water bodies class in order to show the total change into construction as landfill area.

2013-2014 time period (Landsat 8): At this stage, the effects of the construction of the airport have not been seen clearly since the 2013 and 2014 images acquired respectively just before and after the construction start. However, the field work can be seen not only the airport construction area (such as landfill areas of the water bodies, levelling etc.) but also related to the roads connected. The areal extent of the "landfill areas" transformed into "construction area" class on the first time period is relatively small, approximately $166.14 \mathrm{ha}$. One of the biggest changes (3.3\% percentage - 459 ha) were seen in "highly vegetated area" class in this period due to its conversion to the construction area.

2014-2015 time period (Landsat 8): Compared to 2013-2014 time period, the change in 2014-2015 is much higher since the necessary legal permission for construction area of IGA was given on May 12015 by Republic of Turkey General
Directorate of State Airports Authority. In time period of 2014 - 2015, Landsat 8 classification results showed that the areal extents of the changed area from "water bodies" class to "construction area" class was found as 289.41 ha (landfill area). In addition, the changes from "highly vegetated area" class to "construction area" class was about 780 ha (4.9\%) that is higher than other periods.

For the evaluation of the 2015 Sentinel 2A data, 2013 Landsat 8 data was selected as a base image. In this period, change detection results and statistics show that the changes from "highly vegetated area" class to "construction area" class was 625.41 ha $(4.6 \%)$. The biggest change was observed in landfill area (that is from "water bodies" class to "construction area" class) and was calculated as 244.34 ha.

2015-2016 time period (Landsat 8 \& Sentinel 2): Between 2015 and 2016, it was seen that the deforestation process was slightly continuing in the construction area, since most of the clear-cuts for the construction areas of IGA and Northern Marmara Motorway network were accomplished in between 2013 and 2015; i.e. the 78.93 ha (1\%) of "highly vegetated area" class transformed to "construction area" class. The highest change (422.28 ha - 15\%) took place in "construction area" class to "road" class due to Northern Marmara Motorway (Motorway 6) network and construction of first phase of IGA airfield. Besides another change was observed in from "water bodies" class to "construction area" class (237.33 ha as landfill area).

For the Sentinel 2A dataset, the changes from "highly vegetated area" class to "construction area" class was found as 110.25 ha $(1 \%)$. Another major changes were also observed in from "water bodies" class to "construction area" class as landfill area and was calculated as $193.33 \mathrm{ha}$.

2016-2017 time period (Landsat 8 \& Sentinel 2): Between 2016 and 2017, the construction of IGA continued expeditiously. As can be seen the classified images, the final stage of the first airfield and huge part of the main terminal were almost completed and the constructions of Northern Marmara Motorway network continued. Therefore, the "construction area" class was mainly exchanged with the "road" class. As total, $21 \%$ of construction area (760.14 ha in Landsat 8 and 473.82 ha in Sentinel 2A) was changed to "road" class.

The percentage of the changes occurred from "highly vegetated area" class to "construction area" class was determined as approximately $3 \%$ (i.e. 280.44 ha in Landsat 8 and 254.02 ha in Sentinel 2A). Due to ongoing construction, filling the water bodies with excavated soil has continued and found that 145.35 ha from "water bodies" class was changed to "construction area" class. For the Sentinel 2A dataset, this change was computed as 397.72 ha. The reason of this difference between Sentinel 2A and Landsat 8 dataset is due to seasonal changes (such as high differences in precipitation) between the acquisition dates in 2016. Besides the changes can also be seen in from "construction area" class to "road" class in 2015-2016 and 2016-2017 time periods in both datasets. However, total changes between 2015-2017 for both datasets are almost equal to each other. 


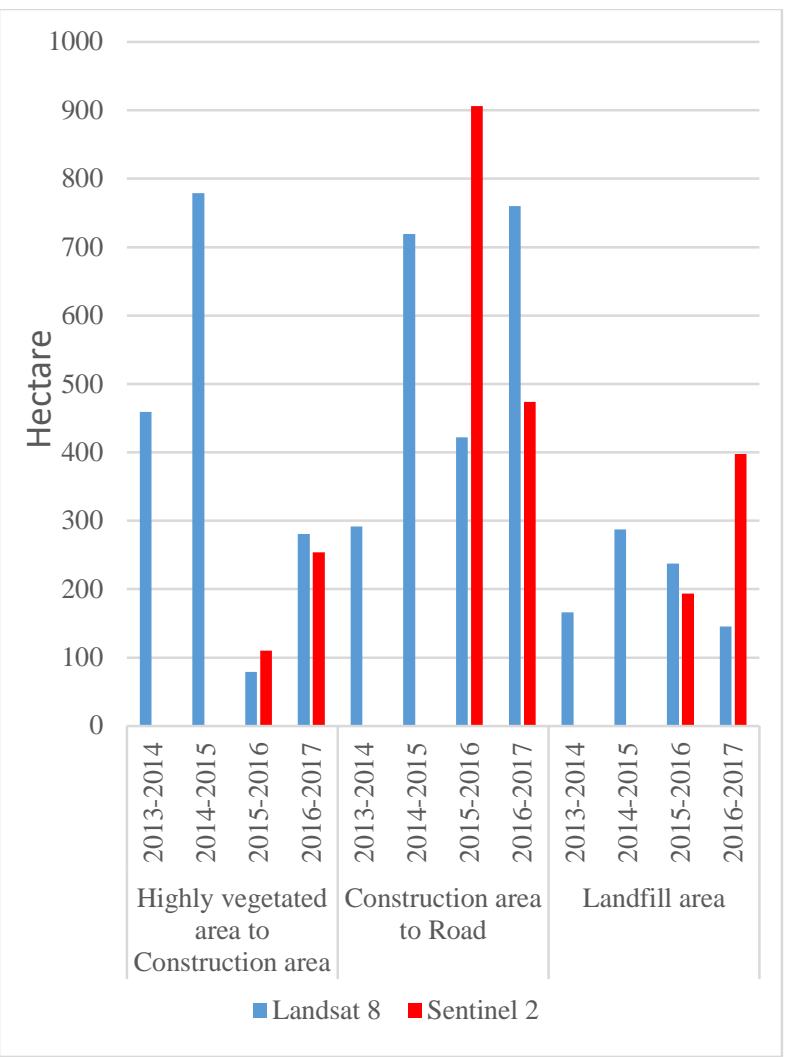

Figure 4 . The change rates of the main classes determined in each time periods.

\section{CONCLUSIONS}

As shown in this study, the multi-temporal Landsat 8 OLI/TIRS and Sentinel 2A MSI satellite datasets covering the Istanbul Grand Airport construction area and its surroundings were classified for detecting the land use/land cover changes occurred gradually. Due to spectral and spatial resolution differences between these datasets, the results of supervised classification were slightly different from each other. To monitor the changes in study area using each dataset, the classified image of 2013 Landsat 8 data was selected as the base image and for comparison, 2013 Landsat 8 data was resampled to 10-meter resolution in order to be used as a reference image for Sentinel 2A dataset. According to change detection analysis done for the time period of 2013 - 2017, the main change was observed in the vegetation class. The areal extents of the change occurred from the "highly vegetated area" class to "construction area" class were found as 1693.5 ha for Landsat 8 and 1669.1 ha for Sentinel 2A. As shown in this study, the findings clearly prove that the serious negative effects were mainly seen on the vegetation cover due to construction of the transportation network, coastline changes nearby the construction site due to landfills and decrease of the natural habitat diversity in the region.
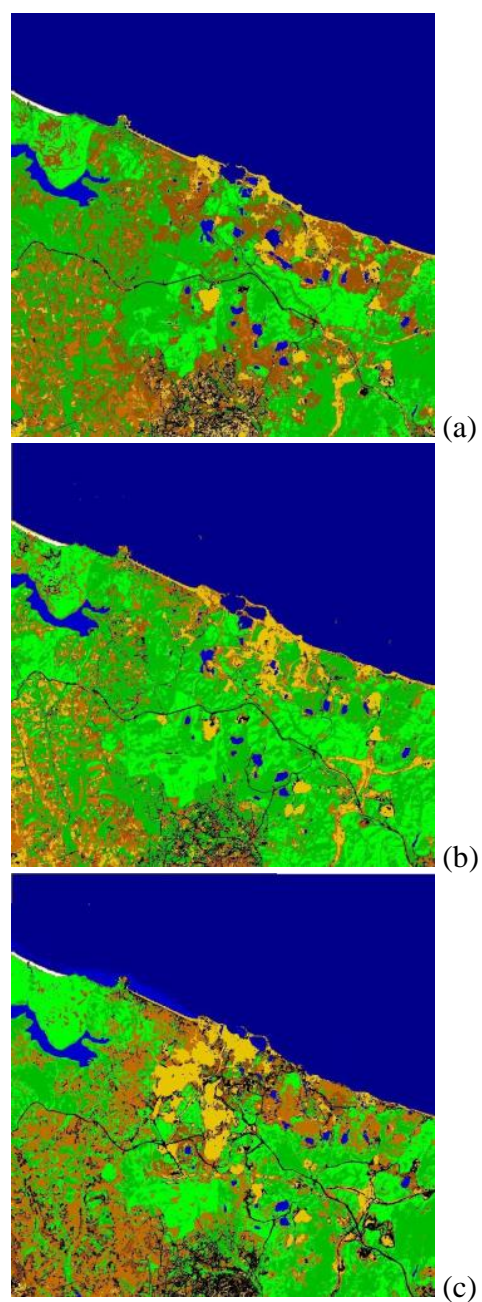

(b)

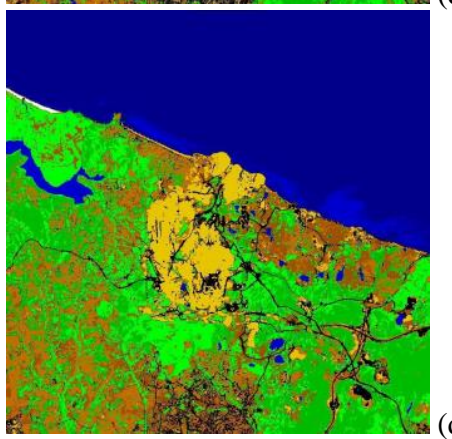

(c)

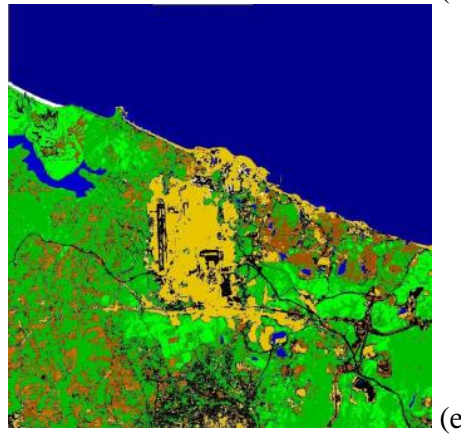

(d)

Figure 5. LULC maps of Landsat 8 datasets (C) USGS) datasets. (a) 2013. (b) 2014. (c) 2015. (d) 2016. (e) 2017. 

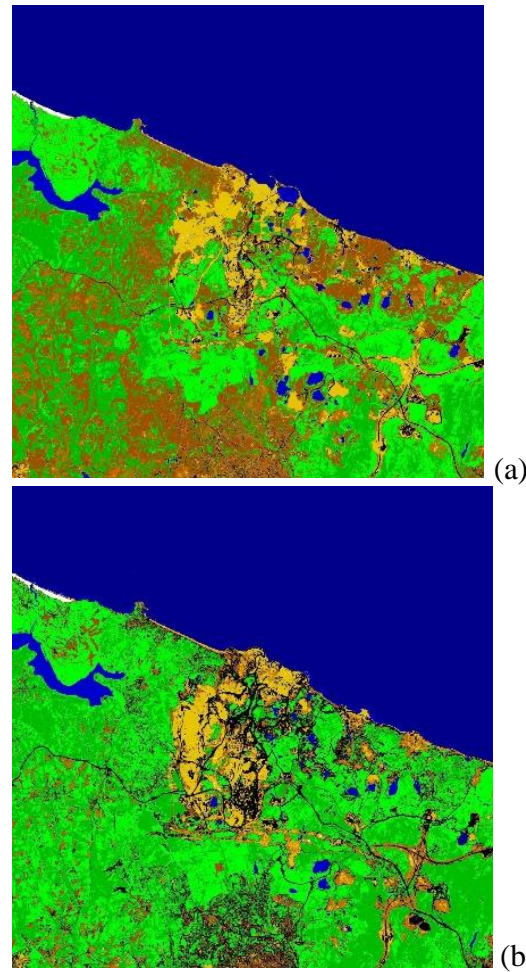

(b)
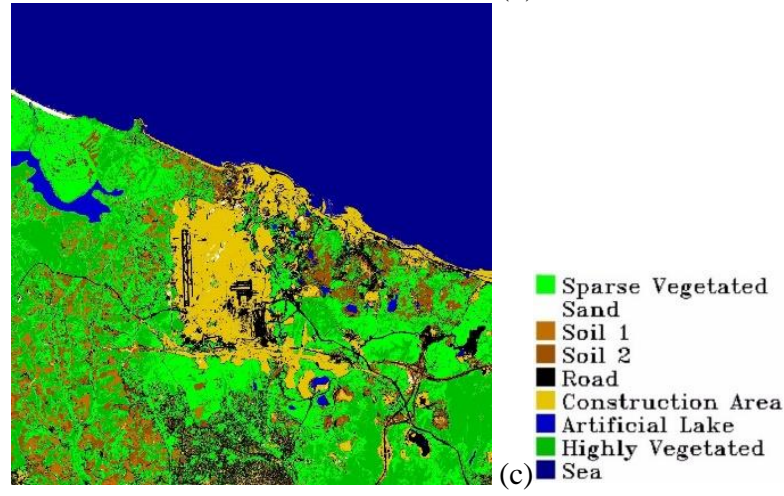

Figure 6. LULC maps of Sentinel 2 MSI datasets (C) ESACopernicus). (a) 2015. (b) 2016. (c) 2017.

Since it is expected that these effects will continue and cause a rapid urbanization (as evidenced by increased road areas) in the area when the IGA project is completed hence; this area needs to be monitored and examined regularly using remote sensing technologies; and the environment and urban planning needs to be regulated carefully not to cause more harmful consequences on the natural ecosystem.

\section{REFERENCES}

Ahmad, A., and Quegan, S., 2012. Analysis of maximum likelihood classification on multispectral data. Applied Mathematical Sciences, 6(129), pp. 6425-6436.
Georgieva, A.D., Düzgün, M., and Tanyaș, M., 2015. The importance of Istanbul Grand Airport (IGA) for Turkey and its influence on widely regional air traffic around. Research in Logistics \& Production, 5(3), pp. 239-254.

Jensen, J.R., 2005. Introductory digital image processing: A remote sensing perspective: Pearson Prentice Hall. Upper Saddle River, NJ.

Macleod, R.D., and Congalton, R.G., 1998. A quantitative comparison of change-detection algorithms for monitoring eelgrass from remotely sensed data. Photogrammetric Engineering and Remote Sensing, 64(3), pp. 207-216.

Muñoz-Marí, J., Bruzzone, L., and Camps-Valls, G., 2007. A support vector domain description approach to supervised classification of remote sensing images. IEEE Transactions on Geoscience and Remote Sensing, 45(8), pp. 2683-2692.

Singh, A., 1989. Review article digital change detection techniques using remotely-sensed data. International Journal of Remote Sensing, 10(6), pp. 989-1003. 